\title{
L-Index Based Weak Area Identification of IEEE 118 Bus System using Dynamic Simulation in PSS ${ }^{\circ} E$
}

\author{
Kamaljyoti Gogoi, Saibal Chatterjee
}

\begin{abstract}
Voltage stability is a relevant part of power system stability analysis ever since many voltage collapse incidences have occurred at different regions of the world. In this paper we take up IEEE 118 bus system as it represents a close approximation of standard Grid system. This IEEE 118-bus system has fixed number of predefined generators, synchronous condensers, transmission lines, transformers and loads. In this work IEEE 118 bus system is simulated and load flow simulation is computed using the software PSS ${ }^{\circledR} E$. The weak buses of the IEEE standard 118 bus network are predicted with the help of L-Index Algorithm in MATLAB. Further dynamic simulation is also performed in the weak buses obtained from L-Index as it opens up scope of more detail analysis of the system. An initial transient disturbance is then introduced in the weak buses and then the resultant maximum frequency deviation and the recovery time of the voltage is computed which finally helps to detect the weak areas in the transmission network. Further Critical Clearing time of the weakest bus is also computed.
\end{abstract}

Keywords: Dynamic Simulation, L-Index, Load flow studies, PSS ${ }^{\circledR E}$, Power system modelling.

\section{INTRODUCTION}

Growth of industry in the nation necessitates highly increased consumption of electrical energy. Increase of load in popular cities have made the transmission system highly essential as generating stations are usually at remote places[1]. The importance of providing energy at distant places in cost effective manner with the ever reducing natural assets have led to the establishment of isolated generating stations and ever improving transmission system[2]. In fast growing economies like India, the demand of load increases after every five to six years so subsequently generating stations number and capacity should also be increased proportionately[3][6][7]. Study of power flow leads to the process of preparation of expansion or modernization of both transmission and generation amenities[4]. Besides planning and designing, ahead of execution of the network, study of load flow is carried out by engineers for ensuring proper and efficient performance and also to ensure that standard safety

Revised Manuscript Received on December 30, 2019.

* Correspondence Author

Kamaljyoti Gogoi*, Department of Electrical Engineering, Nerist, Nirjuli (Arunachal Pradesh) India. E-mail: Kamaljgogoi27@Gmail.Com

Saibal Chatterjee, Department of Electrical And Electronics Engineering, NIT Mizoram, Aizawl (Mizoram) India. E-mail: Saibalda@Ieee.Org

(C) The Authors. Published by Blue Eyes Intelligence Engineering and Sciences Publication (BEIESP). This is an open access article under the CC BY-NC-ND license (http://creativecommons.org/licenses/by-nc-nd/4.0/) measures have been followed[5-6]. Power flow in and out of each of the terminal buses is the summation of power flowing through all the lines linked to that bus[6-7]. Power flow also call as Load Flow is the steady state analysis that determines the current, voltage and power flowing in a network in a given pre-loaded condition[8]. A number of algorithms have been developed that helps in resolving the power flow study cases with the increasing of processing power of computers[5][7].

Major power grids of the world have faced power failure in the past. Cascading failure of Indian Power Grid and maximum line loading capacity of inter-region is discussed in[9].The power grid failure of Israel Electric Corporation is emphasized in [10]. The simulation studies of the North-Western American grid after disturbances and subsequent blackout are described in[11-12]. The details of 2003 North America and Europe grid shutdown are discussed in [13-15], it also analyses the consequences during the power failure. Reference [16-17] discusses the post blackout simulation studies of the Athens grid. The graph theory based topological study of Indian Eastern Grid is described in[18]. Study of various grids [9-18] have led to the need of identification of various parameters like the maximum frequency deviation, the recovery time of the voltage after an initial disturbance and critical clearing time. Since only weak area identification is not enough and severity of the weak area parameters are equally or more important for a viable study of the grid. Identification of weak area of network depending upon weak area of voltage sag based on sag severity index a new index called Bus Performance Index is formed based on which bus performance is calculated is described in [19]. Sag severity index are analyzed and discussed using single-event indices incorporating numerical and fuzzy voltage sag index for weak area identification of the network is described in [20]. A PV analysis based voltage stability analysis to determine weak buses in bulk transmission systems, is discussed in [21]. Weak area identification of power system using different ANN(Artificial Neural Network) algorithm is described along with a comparison between voltage collapse calculation based on ANN and L-index in [22]. Modelling and study of steady state and fault analysis of Indian Eastern and North Eastern Regional grid is studied in[23-24].

The work has been ordered as: Section II defines the IEEE standard 118-bus system, Section III is a brief overview of voltage collapse proximity indicator (L-index), Section IV gives a overview about the software package used to model to IEEE 118 bus system, 
Section V describes about Dynamic simulation and Critical clearing time, Section VI comprises of discussion of the results followed by Section VII where conclusion and the findings are summarized.

\section{DESCRIPTION OF THE SYSTEM}

A part of U.S. Midwest Interconnect System was published in 1962, which latter on became well known as IEEE 118 bus network or system[25-26]. It consists of 118 buses and 177 transmission lines, 9 transformers, 91 loads and 19 generators with a total generation capacity of 4,377 MW and compensators of $574 \mathrm{MW}$ capacity[26]. Out of the 118 buses, 32 bus are generator bus belonging to a single zone. IEEE 118-bus system is one of the more complex and bigger system which represents a close approximation of standard Grid system which is the main reason for choosing this system. Here the standard IEEE 118 bus system shown in Fig 1 has been modelled and load flow simulation is computed using PSS ${ }^{\circ}$ E software.

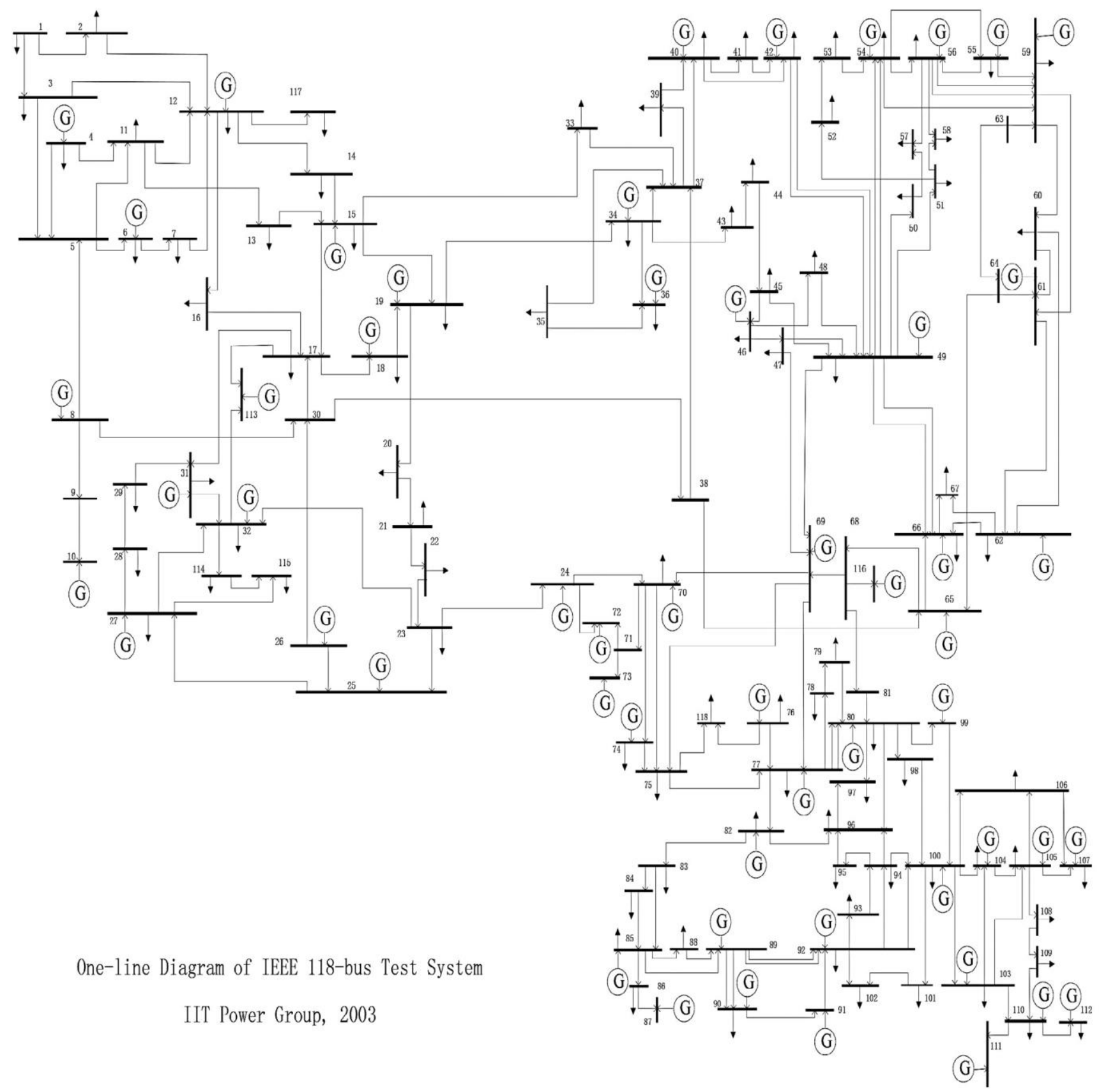

Fig. 1. IEEE 118 BUS Network[26].

\section{L-INDEX VOLTAGE COLLAPSE INDICATOR[30]}

L-Index based voltage collapse indicator was introduced by Kessel and Glavitch [22][30] for the two bus network, subsequently it was generalized for multi-bus network[22]. Considering a network of $x$ number of buses which includes generator buses and load buses as 1, 2, ., g and ( $g+1),(g+2)$ $\ldots, \mathrm{x}$ respectively. A load flow analysis is performed and the

Published By: 
subsequently with its help L-Index value are computed as in (1).

$$
L_{j}=\left|1-\sum_{i=1}^{g} F_{j i} \frac{V_{i}}{V_{j}}\right|
$$

where ,

$j=(\mathrm{g}+1),(\mathrm{g}+2), \ldots, \mathrm{x}$ i.e., $j \in$ set of load buses.

$i \in$ set of generator buses.

$\mathrm{V}_{\mathrm{i}}$ and $\mathrm{V}_{\mathrm{j}}$ are the bus voltages at buses $\mathrm{i}$ and $\mathrm{j}$, respectively.

The values of $\mathrm{F}_{\mathrm{ji}}$ in (1) is obtained from the $\mathrm{Y}$-bus matrix and is given by (2).

$$
\mathrm{F}^{\mathrm{LG}}=\left[\mathrm{Y}^{\mathrm{LL}}\right]^{-1}\left[\mathrm{Y}^{\mathrm{LG}}\right]
$$

where $\left[\mathrm{Y}^{\mathrm{LL}}\right]$ and $\left[\mathrm{Y}^{\mathrm{LG}}\right]$ are sub matrices of the $\mathrm{Y}$-bus matrix[22].

The range of L-Index value is $[0,1]$. When $L$ tends to 1 systems slants towards voltage collapse. The value between L-index and 1 is the load margin or stability margin for a given predefined loading condition[22]. At a given loading condition, load flow analysis is performed and with its help L-index values are computed. The bus having the largest value of L-index is the most prone to voltage collapse]30]. Thus the weakest link within the system can be easily locate thereby, prompting electric power utilities to take protective measures preventing the system to become unstable.

\section{SOFTWARE PACKAGE USED FOR MODELLING[27-29]}

Power System Simulator for Engineering(PSS/E) [27-29] is a program from Siemens Power Transmission \& Distribution, Inc., Power Technologies International (Siemens PTI) for simulating, analyzing and optimizing the performance of power system[27]. User is equipped with vast majority of scenario in different technical areas, including: load flow, fault calculation, dynamic analysis, pricing and policies, transfer interval analysis and network simplification etc. It runs in both graphical user interface mode as well as automation mode which includes all the options like load flow studies, different types of fault analysis, optimal power flow, various switching studies etc. PSS ${ }^{\circledR E}$ also provides the user with wide variety of options like automated raw data input, standard data input, output in different standard format, manipulation, preparation and analysis etc. Additionally user can take the benefit of its computational tools by preparing graphical, tabular or spreadsheet representation. It can also be integrated with different recognised software packages to increase its efficiency and usefulness.

\section{DYNAMIC SIMULATION AND CRITICAL CLEARING TIME}

In dynamic simulation it is assumed that the plant is in a state of change. A dynamic simulation takes time as a variable of consideration. It assumes that the system is in a state of continuous variation with respect to time [31]. Dynamic simulation is used to examine different control techniques, by introducing disturbances or faults to the plant, and seeing how well the controllers respond to the problem. [32-33] Critical Clearing Time (CCT) is the extreme time for which fault can be induced in a system depriving the system of becoming stable[34]. It determines the quality of the protection necessary for the power network. In calculating critical clearing time generally three-phase fault is a constraint which is applied as it shows the transient stability boundary of the system [8]. The basis of this analysis is that it searches within a user-specified data range. Each step of the analysis is performed by an automated run of the program or simulation process thereby producing either unstable or stable states depending upon the time factor [7]. The user determines the stable and unstable states based on his pre-determined conditions specified earlier. The first unstable state and last stable state is hereby fully analyzed to compute the critical clearing time [35].

\section{RESULTS}

IEEE standard 118 bus system has been modelled[36] in this paper using PSS/E. The power flow results has been used to calculate the L-Index of all the buses. The results are then arranged in descending order and buses having higher L-Index value are presented as shown in Table I. The bus having higher L-Index value are more prone to voltage collapse which helps us to predict the weak bus[22].

TABLE I. L-INDEX VALU

\begin{tabular}{|c|c|c|c|}
\hline $\begin{array}{c}\text { Sl. } \\
\text { No. }\end{array}$ & Bus No & $\begin{array}{c}\text { Bus } \\
\text { Voltage }\end{array}$ & L-Index \\
\hline 1 & 95(CALDWELL) & 138 & 0.0158 \\
\hline 2 & 71(NPORTSMT) & 138 & 0.0135 \\
\hline 3 & 44 (WMVERNON) & 138 & 0.0116 \\
\hline 4 & 43 (S.KENTON) & 138 & 0.0113 \\
\hline 5 & 41 (S.TIFFIN) & 138 & 0.0109 \\
\hline 6 & 82(LOGAN) & 138 & 0.0109 \\
\hline 7 & 96(BAILEYSV) & 138 & 0.0096 \\
\hline 8 & 83(SPRIGG) & 138 & 0.0093 \\
\hline 9 & 51(NEWCMRST) & 138 & 0.0089 \\
\hline 10 & 75(STHPOINT) & 138 & 0.0089 \\
\hline
\end{tabular}

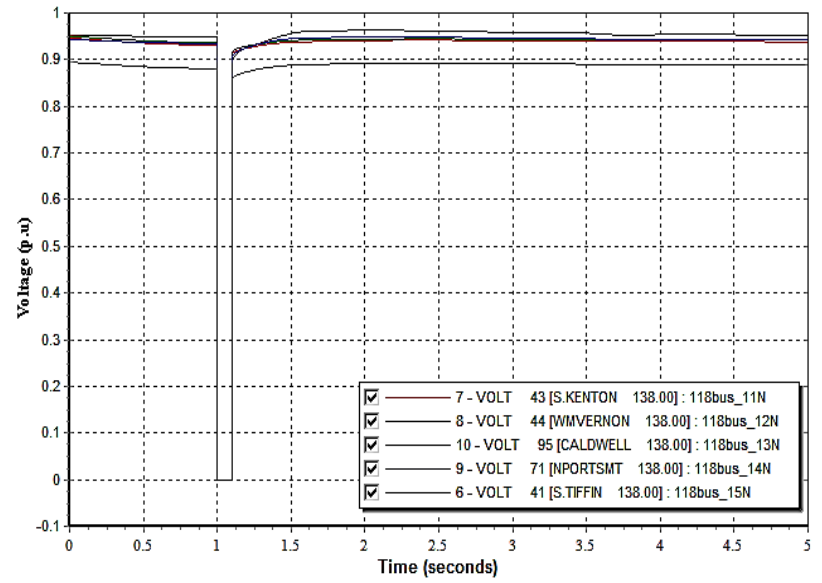

Fig. 2.Recovery time of the voltage.

Further dynamic simulation are performed and buses which takes maximum time to reach a state of stability after the initial disturbance are presented as shown in Table II and buses having higher recovery time are plotted as shown in Fig 2 and Fig 3 respectively.

Published By: 


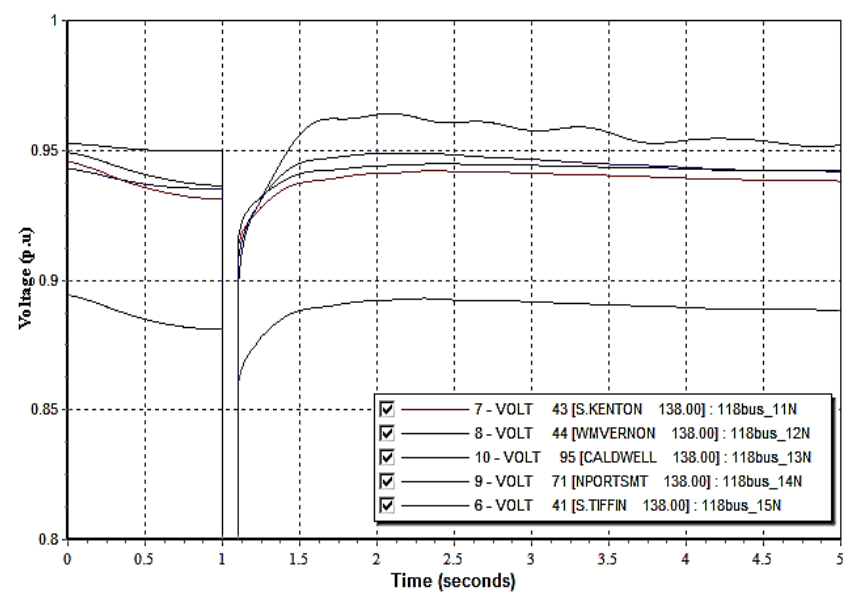

Fig. 3.Enlarged view of the recovery time.

TABLE II. voltage Recovery Time

\begin{tabular}{|c|c|c|c|}
\hline $\begin{array}{c}\text { Sl. } \\
\text { No. }\end{array}$ & Bus No(Name) & Bus Voltage & $\begin{array}{c}\text { Time for } \\
\text { voltage } \\
\text { recovery }\end{array}$ \\
\hline 1 & 95 (CALDWELL) & 138 & 4.624999 \\
\hline 2 & 71 (NPORTSMT) & 138 & 3.616665 \\
\hline 3 & $44($ WMVERNON & 138 & 3.591666 \\
\hline 4 & 43 (S.KENTON) & 138 & 3.399999 \\
\hline 5 & 41 (S.TIFFIN) & 138 & 3.283332 \\
\hline 6 & $82($ LOGAN) & 138 & 3.194799 \\
\hline 7 & $96($ BAILEYSV) & 138 & 3.174899 \\
\hline 8 & 83 (SPRIGG) & 138 & 3.166666 \\
\hline 9 & 51 (NEWCMRST) & 138 & 3.058332 \\
\hline 10 & $75($ STHPOINT) & 138 & 3.041666 \\
\hline
\end{tabular}

\begin{tabular}{|c|c|c|c|c|c|}
\hline $\begin{array}{c}\text { Sl. } \\
\text { No. }\end{array}$ & $\begin{array}{c}\text { Bus Name } \\
\text { (Voltage Level } \\
\mathbf{k V})\end{array}$ & $\begin{array}{c}\text { L-Index Bus } \\
\text { order }\end{array}$ & $\begin{array}{c}\text { Dynamic } \\
\text { simulation Bus } \\
\text { order }\end{array}$ & $\begin{array}{c}\text { Voltage } \\
\text { Recovery } \\
\text { time }\end{array}$ & $\begin{array}{c}\text { Critical } \\
\text { Clearing } \\
\text { Time(ms) }\end{array}$ \\
\hline 1 & $\begin{array}{c}\text { CALDWELL } \\
(138.00)\end{array}$ & 0.0158 & CALDWELL & 4.624999 & 217 \\
\hline
\end{tabular}

\section{ACKNOWLEDGMENT}

This work has been helped and motivated by DST FIST Program project number ETI-211_2007, 28 ${ }^{\text {th }}$ April 2008 and NERIST TEQIP-II Project.

\section{REFERENCES}

1. I. Dobson, B. A. Carreras, and D. E. Newman, "How many occurrences of rare blackout events are needed to estimate event probability?" IEEE Transaction on Power System, Aug. 2013, vol. 28, no. 3, pp. 3509-3510,.

2. P. Hines, J. Apt, and S. Talukdar, "Large blackouts in North America: Historical trends and policy implications," Energy Policy, 2009, vol. 37, no. 12,pp. 5249-5259.

3. J. Kim, J. A. Bucklew, and I. Dobson, "Splitting method for speedy simulation of cascading blackouts," IEEE Transaction on Power System, Aug. 2013,vol. 28, no. 3, pp. 3010-3017.

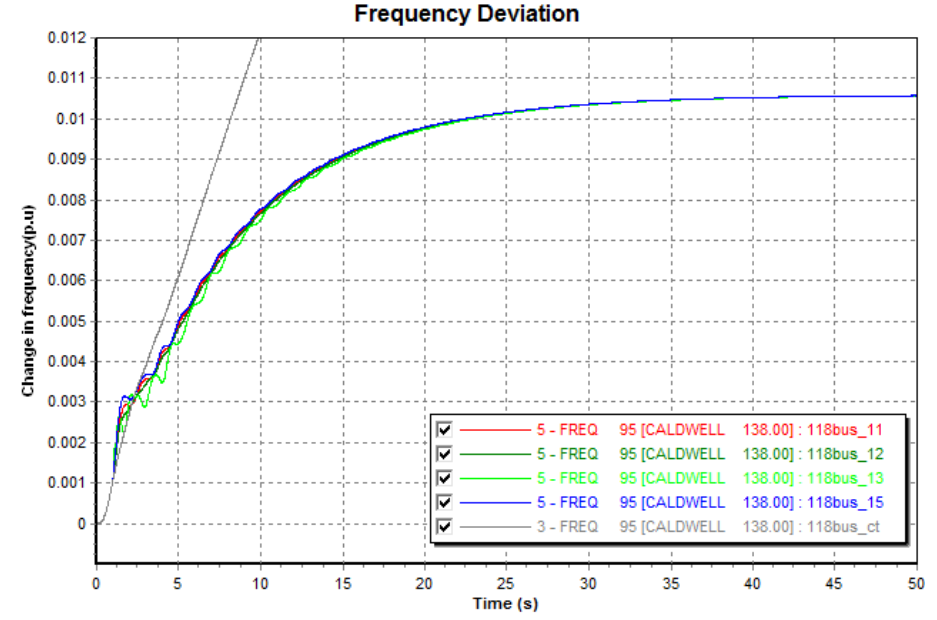

Fig. 4.Calculation of Critical clearing Time

Frequency deviation of Caldwell bus with increase in transient disturbance is shown in Fig 4. Further while calculating critical clearing time transient disturbance was increased by $10 \mathrm{~ms}$ but closer to the probable CCT for better accuracy it was reduced to $1 \mathrm{~ms}$. Critical clearing time of Caldwell Bus is found to be $235 \mathrm{~ms}$ from simulation results.

\section{CONCLUSION}

This work presents a detailed study of IEEE 118 bus network. Power flow analysis is performed after modelling the standard IEEE 118 bus system in PSSE. L-Index of the buses are calculated which predicts the weak bus in the system. 95(CALDWELL) is found to be the most vulnerable bus which is closely followed by 71(NPORTSMT), 44(WMVERNON), 43(S.KENTON) and 41(S.TIFFIN). Further dynamic simulation is also performed at the buses which further validates the weak buses. Thus from the above inference we can conclude that 95(CALDWELL) is the weakest bus and area near it ultimately becomes more prone to voltage collapse as presented in Table III. So necessary precautionary measures should be taken to avoid any cascading failure of the system. The Critical Clearing time from the dynamic simulation was found to be $217 \mathrm{~ms}$.

4. K. R. Padiyar, HVDC Power Transmission Systems - Technology and System Interactions, John Wiley \& Sons. 1990, pp 2-10

5. J. L. Alqueres and J. C. Praca, "The Brazilian power system and the challenge of the Amazon transmission," in Proc. 1991 IEEE Power Engineering Society Transmission and Distribution Conference, pp. 315-320

6. Hadi Saadat, Power System Analysis,13th Edition, Tata McGraw Hill Publications, pp 450-460.

7. D P Kothari and I J Nagrath, Modern Power System Analysis, 4th Edition, Tata McGraw Hill Publication, pp 426-429.

8. P. Kundur, Power System Stability and Control, McGraw-Hill, New York, 1994, pp 23-40

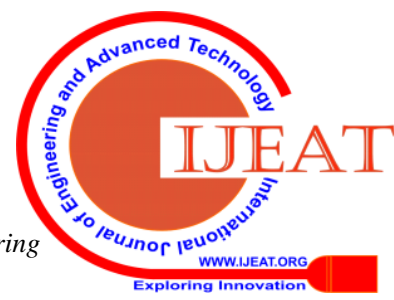


9. V. Rampurkar, P Pentayya, H. V. Mangalvedekar and F. Kazi, "Cascading Failure for Indian Power Grid" IEEE Transactions on Smart Grid, 2016, Volume: 7, Issue: 4.

10. Y. Hain and I. Schweitzer, "Analysis of the power blackout of June 8,1995 in the Israel electric corporation," IEEE Transaction on Power System, Nov. 1997, vol. 12, no. 4, pp. 1752-1758.

11. D. N. Kosterev, C. W. Taylor, and W. A. Mittelstadt, "Model validation for the August 10, 1996 WSCC system outage," IEEE Transaction on Power System, Aug. 1999, vol. 14, no. 3, pp. 967-979.

12. V. Venkatasubramanian and Y. Li, "Analysis of 1996 Western American electric blackouts," in Proc. Bulk Power System Dynamic Control VI, Cortina d'Ampezzo, Italy, Aug. 2004, pp. 685-721.

13. G. Andersson et al., "Causes of the 2003 major grid blackouts in North America and Europe, and recommended means to improve system dynamic performance," IEEE Transaction on Power System, Nov. 2005, vol. 20, no. 4, pp. 1922-1928.

14. C. W. Taylor and D. C. Erickson, "Recording and analyzing the July 2 cascading outage," IEEE Computer Application in Power, Jan. 1997, vol. 10, no. 1 , pp. 26-30.

15. I. A. Hiskens and M. Akke, "Analysis of the Nordel power grid disturbance of January 1, 1997 using trajectory sensitivities," IEEE Transaction on Power System, Aug. 1999, vol. 14, no. 3, pp. 987-994

16. C. D. Vournas, V. C. Nikolaidis, and A. A. Tassoulis, "Postmortem analysis and data validation in the wake of the 2004 Athens blackout," IEEE Transaction on Power System, Aug. 2006, vol. 21, no. 3, pp. 1331-1339.

17. P. Pourbeik, P. S. Kundur, and C. W. Taylor, "The anatomy of a power grid blackout-Root causes and dynamics of recent major blackouts,' IEEE Power Energy Magazine, Sep./Oct. 2006, vol. 4, no. 5, pp. 22-29.

18. V. V. R. V. Chaitanya, D. K. Mohanta and M. Jaya Bharata Reddy, "Topological analysis of eastern region of Indian power grid" 10th International Conference on Environment and Electrical Engineering Rome, Italy $8^{\text {th }}-11^{\text {th }}$ May 2011.

19. Huilian Liao, Sami Abdelrahman, Yue Guo and Jovica V. Milanovic, "Identification of Weak Areas of Network Based on Exposure to Voltage Sags-Part II: Assessment of Network Performance Using Sag Severity Index" IEEE Transactions on Power Delivery, Oct. 2014, Volume: 30 , Issue: 6 , pp. 2401 - 2409.

20. Huilian Liao, Sami Abdelrahman, Yue Guo and Jovica V. Milanovic, "Identification of Weak Areas of Power Network Based on Exposure to Voltage Sags - Part I: Development of Sag Severity Index for Single-Event Characterization" IEEE Transactions on Power Delivery, Oct. 2014, Volume: 30 , Issue: 6 , pp. $2392-2400$.

21. T. He, S. Kolluri, S. Mandal, F. Galvan and P. Rasigoufard, "Identification of weak locations in bulk transmission systems using voltage stability margin index", IEEE Power Engineering Society General Meeting, Denver, CO, USA, $6^{\text {th }}-10^{\text {th }}$ June 2004.

22. G. Shankar; V. Mukherjee; S. Debnath; K. Gogoi, "Study of different ANN algorithms for weak area identification of power systems" 1 st International Conference on Power and Energy in NERIST, 28th -29th Dec 2012.

23. Toushik Maiti, Kamaljyoti Gogoi and Saibal Chatterjee, "Modelling and study of Indian Eastern Regional Grid using PSS ${ }^{\circledR} E, 12^{\text {th }}$ IEEE India International conference INDICON-2015, $17^{\text {th }}-20^{\text {th }}$ December 2015, Jamia Millia Islamia, New Delhi.

24. Kamaljyoti Gogoi, Diganta Misra, Nrilanjan Debnath, and Saibal Chatterjee, "Modelling and study of steady state analysis and fault parameters in $400 \mathrm{kV}$ and $220 \mathrm{kV}$ buses of Indian North Eastern Regional Grid" International Conference on Energy, Power and Enviroment, Shillong, $12^{\text {th }}-13^{\text {th }}$ June 2015.

25. Ivonne Peña ,Carlo Brancucci Martinez-Anido, and Bri-Mathias Hodge , "An Extended IEEE 118-Bus Test System With High Renewable Penetration" IEEE Transactions on Power Systems Jan. 2018, Volume: 33 , Issue: 1 .

26. 118 Bus Power Flow Test Case [Online] Available: http://labs. .ece.uw.edu/pstca/pf118/pg_tca118bus.htm

27. $\mathrm{PSS} \circledast \mathrm{E}$ Lab Manual of Colorado State University.

28. PSS $\AA^{\circledR}$ 33.3 Program Application Guide Volume I.

29. PSS $® E$ Documentation, Website: http://w3.siemens.com/smartgrid/global/en/products-systems-solutions/software-solutions/planningdata m-anagement-software/planning-imulation/pages/psse.aspx.

30. P. Kessel, and H. Glavitsch, "Estimating the voltage stability of a power system," IEEE-Trans. PWRD, vol. 1, no. 3, pp. 346-354, July 1986.

31. Z. Huang, S. Jin, and R. Diao, "Predictive dynamic simulation for large-scale power systems through high-performance computing," in Proc. High Performance Computing, Networking, Storage and Anal., 2012, pp. 347-354.
32. Arfah Marini Mohamad, Norazlan Hashim, Noraliza Hamzah, Nik Fasdi Nik Ismail, Mohd Fuad Abdul Latip, "Transient Stability Analysis on Sarawak's Grid using Power System Simulator Power System Simulator for Engineering (PSS/E)", IEEE Symposium on Industrial Electronics and Applications (ISIEA), Sept. 25-28, 2011, Langkawi, Malaysia.

33. J. P. Yang, G.H.Cheng, Z.Xu," Dynamic Reduction of Large Power System in PSS/E", IEEE/PES Transmission and distriution Conference \& Exhibition : Asia and Pacific Dalian, China, 2005.

34. Naoto Yorino, Ardyono Priyadi, Hironori Kakui and Mitsuhiro Takeshita," A New Method for Obtaining Critical Clearing Time for Transient Stability" IEEE Transactions on Power Systems, vol. 25, Issue: 3 , Aug. 2010

35. Lewis G. W. Roberts, Alan R. Champneys, Keith R. W. Bell and Mario di Bernardo, "Analytical Approximations of Critical Clearing Time for Parametric Analysis of Power System Transient Stability", IEEE Journal on Emerging and Selected Topics in Circuits and Systems, vol. 5, Issue: 3, p. 465-476, August 2015.

36. IEC 60909 , First Edition 2001-07, International Standards.

\section{AUTHORS PROFILE}

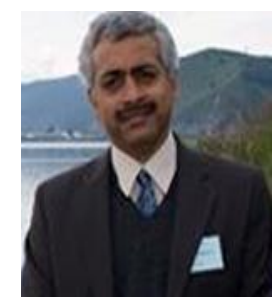

Saibal Chatterjee (M'2007, SM'13) was born in West Bengal, India on January 12, 1969. He did his graduation from NIT Durgapur. He did his post-graduation and $\mathrm{PhD}$ from Jadavpur University. He did his PGDIM from IGNOU. His employment experience includes as Sales Engineer in ORG Limited, Howrah for 12 month. He also worked as Shop Floor Engineer and Design Engineer in Marson's Limited, Kolkata for 3 years. He also worked as Lecturer, Assistant Professor, Associate Professor and Professor for 21 years in NERIST. He is now working as Professor in NIT Mizoram.

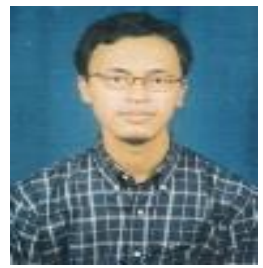

Kamaljyoti Gogoi (M'2014) was born in Bishwanath Chariali, Assam, on March 29, 1986. He did his graduation and post-graduation from NERIST (Deemed University). He did his MBA from SHIATS. His employment experience includes as a Site Engg. in BCPL and NEECON for 18 months. 